\title{
A APROPRIAÇÃO DAS TECNOLOGIAS DE INFORMAÇÃO DE COMUNICAÇÃO EM AMBIENTE DE EAD MEDIADO POR COMPUTADOR: uma experiência no PROINESP com PNEEs com limitação visual
}

\author{
Eliane Lourdes da Silva Moro ${ }^{1}$ \\ Lizandra Brasil Estabel ${ }^{2}$ \\ Lucila Maria Costi Santarosa ${ }^{3}$
}

\begin{abstract}
RESUMO: O artigo apresenta o processo da leitura no âmbito da família extensivo à escola e à biblioteca, incentivando-a de forma prazerosa e lúdica, formando um leitor com habilidade para a crítica e para a reflexão e recuperando o clima afetivo que a leitura propicia. Aborda as TICs em uma perspectiva de acesso e de uso, através da interação, do compartilhamento e da cooperação entre as pessoas, possibilitando a inclusão social e digital. Apresenta o acesso à informação através das tecnologias e do sistema Braille utilizado pelas Pessoas com Necessidades Educacionais Especiais (PNEEs) com limitação visual. Relata a experiência vivenciada na realização do PROINESP através do Curso de Formação em Serviço de Professores em Informática na Educação Especial, na modalidade de Educação a Distância mediada por computador, tendo como sujeitos professores com limitação visual, utilizando as ferramentas tecnológicas, através das narrativas e memórias afetivas.
\end{abstract}

PALAVRAS-CHAVE: Leitura; Inclusão Social e Digital; Tecnologias de Informação e de Comunicação; Pessoas com Necessidades Especiais com Limitação Visual.

ABSTRACT: The article presents the process of the reading in the scope of the extensive family to the school and the library, stimulating it of pleasant and playful form, forming a reader with ability for the critical one and the reflection and recouping the affective climate that the reading propitiates. It approaches the TICs in a perspective of access and use, through the interaction, of the sharing and the cooperation between the people, making possible the social and digital inclusion. It presents the access to the information through the technologies and of the system Braille used for the People with Educational Necessities Special with visual limitation. It tells the experience lived deeply in the accomplishment of the PROINESP through the Course of Formation in Service of Professors in Computer science in the Special Education, the modality of Education in the distance mediated by computer, having as citizens professors with visual limitation, using the technological tools, through the affective narratives and memories.

KEY-WORDS: Reading; Social and Digital inclusion; Technologies of Information and Communication; People with Necessities Special with Visual Limitation.

\section{INTRODUÇÃo}

\footnotetext{
1 Professora do Curso de Biblioteconomia da FABICO/UFRGS, Especialista em Informática na Educação PGIE/UFRGS, Aluna do Programa de Pós-Graduação em Educação da UFRGS - PPGEdu/UFRGS, Coordenadora do Núcleo da Hora do Conto do DCI/FABICO/UFRGS e Membro do Nucleo de Informática na Educação Especial (NIEE/UFRGS).

E-mail: eliane_moro@yahoo.com.br.

${ }^{2}$ Formadora do PROINESP 2005. Aluna do Doutorado de Informática na Educação - PGIE/UFRGS, Bibliotecária do Colégio Mãe de Deus e do Instituto Santa Luzia. Membro do Núcleo da Hora do Conto do DCI/FABICO/UFRGS e do Nucleo de Informática na Educação Especial (NIEE/UFRGS). E-mail:estabel@cpovo.net .

${ }^{3}$ Professora Doutora do PPGEDU e do PGIE/UFRGS, Coordenadora Nacional da RIBIE, Coordenadora de pesquisa do NIEE/UFRGS, E-mail: lucila.santarosa@ufrgs.br

V. $3 \mathrm{~N}^{\circ} 2$, Novembro 2005
} 
Vive-se em uma sociedade de diferenças, de diversidades. As tecnologias foram criadas pelo homem para facilitar a sua vida, serem a extensão do seu braço no trabalho, como forma de proteção, de criação. Hoje, ao imprimir alguns pontos em um papel, a pessoa com limitação visual têm acesso à leitura e à escrita. O surgimento do sistema Braille em 1825, permitiu que as pessoas com limitação visual passassem a ter contato com a cultura letrada. Antes disso, essas pessoas utilizavam a oralidade para passar a informação, permitindo que se realizasse o processo de comunicação, mas havendo a necessidade de um registro. Pode-se observar o hiato desde 0 surgimento da escrita de três a cinco mil anos da Era Cristã entre o acesso pelas pessoas com visão normal e as pessoas com limitação visual. Com o surgimento do Braille, as diferentes combinações de sessenta e três pontos impressos no papel, conectou a pessoa com limitação visual com o mundo da leitura e da escrita.

Este artigo tem como foco o uso das Tecnologias de Informação e de Comunicação (TICs) no processo de interação entre pessoas participantes de qualificação profissional na atuação do exercício do pedagógico, através da informática na educação, visando sobretudo a inclusão social e digital e o exercício da cidadania. Em um país em que o índice de leitura é ínfimo, o acesso à informação é deficiente e permeado de obstáculos, a cidadania e a inclusão social e digital são propostas públicas onde poucos se propõem à ação de propiciar e permitir, onde a ética se faz necessária e urgente e onde a educação e a saúde devem ser prioridades, surge o Programa Nacional de Informática na Educação Especial (PROINESP), realizando o Curso de Formação em Serviço de Professores em Informática na Educação Especial. $O$ Programa foi executado pelo Núcleo de Informática na Educação Especial (NIEE), da Universidade Federal do Rio Grande do Sul (UFRGS), coordenado pela Prof. Dra Lucila Maria Costi Santarosa e realizado no período de março a junho de 2005. Diversos trabalhos foram elaborados pelos formadores participantes do Curso e apresentados em Eventos Científicos na área de Educação Especial e Informática na Educação, abordando os mais diversos aspectos e âmbitos pedagógicos no que se refere à inclusão, à cidadania, à interação, às Pessoas com Necessidades Educacionais Especiais (PNEEs), às TICs, às ferramentas eletrônicas, entre outros.

Este trabalho apresenta o processo da leitura que se inicia na família e deveria continuar na escola e na biblioteca, incentivando a leitura de forma prazerosa e lúdica, formando um leitor com habilidade para a crítica e para a reflexão e recuperando o clima afetivo que a leitura propicia no âmbito em que se realiza. Apresenta também as TICs em uma perspectiva de acesso e de uso, através da interação, do compartilhamento e da cooperação entre as pessoas, possibilitando a inclusão social e digital. Na abordagem das TICs e as PNEEs com limitação visual, relata a experiência vivenciada no PROINESP através do Curso de Formação em Serviço de Professores em Informática na Educação Especial, realizado no decorrer de 2005, tendo como sujeitos professores (inscritos no Curso) e alunos destes professores, todos com limitação visual, utilizando as ferramentas tecnológicas, através das narrativas e memórias afetivas. 
O processo da leitura na escola e na biblioteca deveria ter seu início na família, sem que esta postergue para a escola o papel da formação do leitor e do incentivo à leitura. A primeira experiência de leitura já vem impregnada de afeto, caracterizada pelas primeiras interações da mãe com seu filho ainda no ventre materno, quando, ao acariciar sua barriga, compartilha com a criança o processo de comunicação. Essa comunicação não tem como suporte o emissor e o receptor, mas o expressor - a mãe - e o perceptor - o filho, isto é, aquele que expressa e aquele que percebe. A interação na comunicação continua após o nascimento, quando as cantigas de ninar acalantam e acalmam o bebê conduzindo-o para um sono tranqüilo e embalado pela suave melodia da voz materna. Nos anos seguintes, esse compartilhamento de afetos continua através das histórias narradas, pelas pessoas que fazem parte do círculo de afeto das crianças: além da mãe, o pai, o irmão ou irmã maiores, o tio ou a tia, o avô ou a avó, a babá, entre outros contadores de histórias. Nesse encontro mágico e prazeroso, permeado de causos e narrações de aventuras, de terror, de lendas e mitos, ou de histórias de vida onde os personagens são próximos, os sonhos, a fantasia, a magia, a aventura e o ludismo permeiam o imaginário das crianças que ouvem as narrativas e estabelecem laços de afeto entre quem conta e quem ouve histórias.

Segundo Estabel e Moro (2005, p.3) "o papel da família nos primeiros contatos entre a criança e as narrativas é fundamental". Pode-se dizer que a família é a primeira mediadora de leitura.

Ao chegar na idade escolar, se a criança não vivenciou o prazer de ouvir histórias no contexto familiar, a escola vai influenciar, positiva ou negativamente, na formação do leitor, dependendo das ações de leitura desenvolvidas pelos professores ou das políticas de leitura previstas no Projeto Político Pedagógico da instituição. Se o professor for leitor e gostar de ler ele passa aos seus alunos a paixão e o prazer da leitura. Quando o professor não lê e trabalha a leitura na sala de aula, como um processo mecânico, através da decodificação de sinais escritos, do ato de reprodução textual sem interação, sem a existência do elo entre o texto, o contexto e o leitor, temos como resultado a pseudoleitura, onde o leitor se caracteriza como consumidor passivo de mensagens não significativas e irrelevantes.

Quando a escola incentiva leitura, a ação do professor se desenvolve com atividades que oportunizam e estimulam a leitura crítica e reflexiva. A leitura crítica se processa através do ato de compreensão e de conhecimento, propiciando a relação entre o leitor, o texto e o autor, tomando consciência do significado do texto, transformando-o, re-elaborando-o e re-escrevendo-o. 0 leitor, aqui considerado sujeito, executa atividades de constatação, de cotejo, de transformação através da leitura que possibilita a reflexão, a crítica, a participação e o posicionamento. 
Em uma sociedade que não lê, a conquista da leitura é o primeiro passo para a formação dos valores da sociedade, propiciando a participação social, compreensão do homem pelo homem, nível cultural, forma de lazer, formação e exercício da cidadania, entre outros. A formação do leitor envolve os aspectos político, psicológico e metodológico através das ações de leitura, considerada como um processo constante de esforços conscientes da área educacional.

A família e os professores devem ser partícipes nas ações de leitura implementadas na escola e, a biblioteca, deve ser a parceira constante nas políticas de leitura.

Conforme Estabel e Moro (2005, p.8) "o papel do bibliotecário é o de mediador entre a leitura, a informação e o leitor. Este profissional, além de orientar o usuário no uso dos suportes informacionais, deve ser um promotor de leitura e, além de tudo, um bibliotecário educador".

A biblioteca deve ser o espaço mágico do prazer da leitura, através de atividades que atendam a criança, o adolescente e o adulto, incluindo, além das graduações de ensino e a faixa etária, as diferentes peculiaridades das pessoas, níveis e maturidades de leitura. Além disso, a biblioteca escolar abrange a comunidade externa da escola, atendendo as pessoas sem vínculo com a instituição, mas situadas geograficamente próximas à escola. As políticas de leitura devem atender desde a criança ainda não alfabetizada até o ancião quase centenário que busca informação, incluindo também as PNEEs. Além disso, o professor e o bibliotecário, podem disponibilizar diferentes suportes de leitura aos usuários, através das TICs utilizando textos bibliográficos e eletrônicos.

\title{
3 AS TECNOLOGIAS DE INFORMAÇÃO E DE COMUNICAÇÃO E A INCLUSÃO SOCIAL ATRAVÉS DA INTERAÇÃO
}

As TICs possibilitam o acesso à informação, a interação entre as pessoas e a construção de materiais de aprendizagem facilitando o uso da multimídia que torna mais efetivo o ambiente de aprendizagem apoiado nas ferramentas tecnológicas e propiciando o processo de transformação da aprendizagem que inicia social e vai tornando-se individual. Vygotsky (1998) considera a aprendizagem como um processo social no qual os sujeitos constroem seus conhecimentos através da sua interação com o meio e com os outros, numa inter-relação constante entre fatores internos e externos.

\begin{abstract}
As habilidades cognitivas construídas pelos sujeitos estão relacionadas diretamente com a maneira como acontece a interação com os outros num ambiente específico de solução de problemas. Sendo, portanto, o papel da escola criar contextos sociais para interação, pois é pelo domínio das ferramentas de representação e comunicação, que os sujeitos adquirem capacidade e meios para uma atividade intelectual superior. (PASSERINO; SANTAROSA, 2004).
\end{abstract}

A utilização das TICs através do computador introduziu um novo elemento no processo de comunicação: a interatividade a qual, na visão de Nuñez (2000, p.58) "promete revolucionar os esquemas atuais de comunicação 
ao transformar os receptores em emissores ativos das mensagens." A interatividade permite ao computador tornar-se uma via de duas mãos, uma vez que significa a relação entre duas ou mais pessoas, interagindo mutuamente, com a finalidade de atingir o mesmo objetivo.

A importância do uso das TICs pode ser evidenciada na interação entre PNEEs com limitação visual que possibilitaram verificar a superação das dificuldades a partir do compartilhamento de um com o outro e de um com os outros. O indivíduo é responsável pelo seu aprendizado e pelo aprendizado do outro e dos outros. Para que a aprendizagem se realize, é necessário que haja um processo de troca, de construção colaborativa e cooperativa mediados por instrumentos que possibilitem o acesso destas pessoas ao ambiente digital e 0 uso das TICs.

Para Santarosa (2002) as TICs significam "uma nova janela que se abre" com o intuito de minimizar a exclusão social existente em nossa sociedade com relação às PNEEs, na maioria das vezes, consideradas como "incapazes de lidar e manusear com instrumentos mais sofisticados como são os computadores". As TICs podem contribuir, de alguma forma, para reforçar a importância da inclusão social e digital das PNEEs em nossa sociedade, nas escolas, universidades, bibliotecas, empresas, entre outros, onde a maioria das pessoas está incluída. Constata-se a necessidade de adaptar e adequar os espaços físicos desses ambientes, buscando maneiras de inserir estas pessoas em ambientes adaptados às suas necessidades.

\section{AS TECNOLOGIAS DE INFORMAÇÃO E DE COMUNICAÇÃO E AS PNEES COM LIMITAÇÃO VISUAL}

O acesso à informação pelas PNEEs com limitação visual muitas vezes é dificultado pela falta de materiais adaptados e/ou pela falta de disponibilidade de pessoas que façam a mediação entre o leitor e o texto. Muitos empecilhos impostos pela falta de uma condição mais adequada de acesso à informação podem levar a pessoa com limitação visual, com cegueira ou baixa visão, a sentir-se excluída do processo de leitura causando um desânimo e prejudicando o processo de autonomia do sujeito na construção do conhecimento.

Sabe-se da dificuldade de acesso a um livro Braille, da disponibilidade das pessoas de serem leitores, da falta de equipamentos adaptados e de informação das pessoas da sociedade sobre o uso das TICs pelas pessoas com limitação visual.

Segundo Vygotsky (1997, p.83) a cegueira, que só priva de um "puro estímulo físico" não cerra hermeticamente as janelas ao mundo, não priva da "realidade" completa. Só compele a interpretação social destes estímulos físicos a transpor-se para outros estímulos e a vincular-se com estes. Pode ser compensada em maior medida por outros estímulos. "O importante é aprender a ler e não simplesmente ver as letras. O importante é reconhecer as pessoas e compreender seu estado, e não mirá-las nos olhos."

Diante do exposto, poder-se-ia afirmar que tantas dificuldades apresentadas seriam motivos suficientes para que estas pessoas não participassem de um curso de educação a distância, que os custos de um livro Braille poderiam inviabilizar a inserção destas pessoas com limitação visual nas escolas, nas bibliotecas, nas empresas, entre outros. No entanto, acredita-se 
que é possível ir muito além do que uma avaliação simplista e de fácil desistência.

O uso das TICs e a possibilidade de acesso à Internet permitem que as pessoas com limitação visual possam fazer uso destes recursos para a sua formação incluindo-as em um Ambiente de Aprendizagem Mediado por Computador (AAMC) onde passam a ser agentes ativos do seu processo de aprendizagem. Através da interação com o outro, com o grupo, a pessoa com limitação visual sente-se parte deste universo adquirindo autonomia e melhorando a sua auto-estima, sentindo-se capaz. Neste novo cenário educacional, acredita-se que cada ator deve ser co-participante do seu aprendizado e do grupo. Professores e alunos são responsáveis por este processo. Ações de cooperação permitirão que limitações impostas pelas tecnologias sejam superadas através do compartilhamento das dificuldades buscando soluções para os problemas apresentados. O professor que possui limitação visual, ao fazer parte deste cenário, sentir-se-á estimulado a fazer uso das tecnologias com seus alunos, este com ou sem limitação visual, sendo um agente de inclusão social e digital.

Lopes (2005, p.49) referindo-se aos novos ambientes de aprendizagem afirma que estes exigem do educador-pesquisador a "competência de saber trocar saberes, habilidades para construir e reconstruir com seus alunos conhecimentos significativos, para conhecer o erro como fator de construção e saber lidar com as incertezas, as transitoriedades, os problemas."

O professor deve encantar os seus alunos propiciando o diálogo, a interação, a criatividade, o compartilhamento. $O$ ambiente digital deve ser agradável, prazeroso possibilitando que o aluno sinta-se capaz de produzir, de criar, de construir. A conjugação destes verbos possibilita que o sujeito adquira autonomia e que a sua limitação visual seja superada através de outros mecanismos de compensação permitindo que professores e alunos aprendam conjuntamente e façam novas descobertas. Vygotsky (1997, p.116) afirma que quando estamos diante de uma criança cega como objeto de educação temos que operar não tanto com a cegueira em si, quanto com os conflitos que se criam na criança cega ao incorporar-se à vida, pois suas relações com o mundo circundante começam a fluir por um caso distinto que a de pessoas normais.

\section{CAPACITANDO PROFESSORES NA INFORMÁTICA DA EDUCAÇÃO ATRAVÉS DO PROINESP E INCLUINDO ALUNOS NO AMBIENTE DIGITAL E NO EXERCÍCIO DA CIDADANIA}

No cenário brasileiro, o acesso à escola muitas vezes é dificultado pela falta de informação, de educação e de comunicação. Por outro lado constatase a desmotivação dos professores, a falta de qualidade no uso das TICs para o processo de aprendizagem e a dificuldade dos profissionais da educação na relação com as PNEEs com limitação visual, surdos, com síndrome de down, entre outros.

As escolas não possuem materiais adaptados para este público, com raras exceções, como obras em Braille, sistema de escrita das PNEs com limitação visual, ou equipamentos tecnológicos adaptados para atendê-los em suas necessidades. A dificuldade de acesso às TICs é um outro problema enfrentado pelos cegos, pois as bibliotecas não 
disponibilizam materiais especiais como livros em Braille, fitas sonoras, entre outros. Verifica-se uma grande dificuldade de produção e distribuição desses livros especiais, pois é necessário digitá-los ou digitalizá-los para depois imprimi-los em uma impressora Braille. (ESTABEL ; MORO, 2005).

Conforme Santarosa (2001) os ambientes virtuais favorecem a comunicação entre pessoas dispersas geograficamente e "possibilitam a troca e o intercâmbio, a criação e a produção de informações e materiais cooperativos, transformando-se em um ambiente de dialogismo generalizado que resulta em um pensar coletivo".

Segundo Estabel e Moro (2005), no Brasil existem 20.257 alunos com limitação visual na educação básica do sistema educacional brasileiro.

Faz-se necessário a capacitação de professores para melhor atender a estes alunos mas, com uma proposta de construção colaborativa, propiciando a estes alunos autonomia, através da construção com o outro. As dificuldades a serem superadas são muitas: de acesso à informação, aos materiais especiais adequados que atendam as suas necessidades, ao uso de tecnologias assistivas e adaptativas, mas principalmente de uma postura do professor de mediador deste processo, propiciando ao aluno um papel ativo na construção de seu conhecimento. A busca da superação das limitações está dentro do ser humano, basta acreditar e construir.

O PROINESP, da Secretaria de Educação Especial (SEEsp) do Ministério da Educação (ME) ofereceu o Curso de Formação em Serviço de Professores em Informática na Educação Especial ano de 2005, executado e ministrado pela equipe do Núcleo de Informática na Educação Especial (NIEE), da Universidade Federal do Rio Grande do Sul (UFRGS), coordenado pela Prof. Dra Lucila Maria Costi Santarosa. O curso iniciou em março de $2005 \mathrm{com}$ a carga horária de $120 \mathrm{~h}$ e o encerrou no mês de junho de 2005. Participaram aproximadamente 310 professores, de 155 escolas públicas e instituições nãogovernamentais contempladas com laboratórios de informática. Dentre outros objetivos gerais do Curso, pode-se destacar os seguintes: formar em serviço, via Internet, os professores de escolas públicas municipais e estaduais e de entidades de educação especial no uso pedagógico das TICs e auxiliar os professores na implantação, nas respectivas instituições, de atividades de uso das TICs, integradas às atividades curriculares que desenvolvem, junto aos seus alunos especiais.

A metodologia do Curso foi desenvolvida totalmente a distância, mediada por computador, utilizando o ambiente eletrônico TelEduc, centrada na realização das atividades solicitadas, na interação do professor com o ambiente, no trabalho com alunos, na participação em fóruns, bate-papo, interação com os colegas e os formadores/monitores e auto-avaliação. $O$ TelEduc se caracteriza como um ambiente de fácil utilização e apresenta ferramentas de comunicação como: correio eletrônico, diário de bordo, fórum de discussão, mural, bate-papo, entre outras.

Sobre as tecnologias utilizadas e a acessibilidade, uma aluna, PNEEs com limitação visual registrou em uma mensagem do "Fórum" do ambiente TelEduc:

Já trabalho dando aulas de Dosvox a alunos portadores de deficiência visual. E este ano tivemos uma grande conquista na 
área da informática no nosso trabalho, pois conseguimos instalar a internet veloz em nossos sistemas. Que bom que a tecnologia vem sendo utilizada também para dar acesso a todo um universo de informações antes inacessíveis para pessoas com algum tipo de necessidade especial. Torço para que os órgãos governamentais continuem olhando para este lado da sociedade tão discriminada, mostrando a capacidade que temos. (Professora/aluna 1). (http://teleduc.proinesp.ufrgs.br/cursos/aplic/index.php?cod curso=9).

A avaliação dos participantes do Curso envolveu um processo de acompanhamento contínuo dos formadores em cada uma das disciplinas e em todas atividades realizadas.

\section{UMA EXPERIÊNCIA EM EAD COM PROFESSORES E ALUNOS: AS NARRATIVAS COMO SUPORTE DE CRIAÇÃO DE OBJETOS DE APRENDIZAGEM ATRAVÉS DAS MEMÓRIAS AFETIVAS DE PNEES COM LIMITAÇÃO VISUAL}

Os professores inscritos no PROINESP foram selecionados em quinze turmas, de aproximadamente 22 participantes cada uma, oriundos de instituições educacionais das mais diversas regiões do Brasil. Em uma das turmas, dentre os participantes, havia quatro professores com necessidades especiais com limitação visual, sendo que uma delas além de psicopedagoga é também bibliotecária.

Na semana 13 do PROINESP, foi solicitado aos professores/alunos que realizassem uma atividade prática de criação de histórias em quadrinhos com os seus alunos. Foi indicado o uso dos softwares educacionais "HagáQue" e "Turma da Mônica". Como estes softwares possuem recursos basicamente visuais, sendo o som apenas um complemento para ilustrar as histórias, estes softwares não seriam os mais indicados para o uso de alunos com limitação visual e nem pelas professoras, pois estas também possuem limitação visual. Diante das dificuldades apresentadas surgiu a idéia de fazer o uso de outros softwares, com recursos de áudio, mas com o mesmo objetivo de criação de histórias pelos alunos.

As professoras 1 e 2 atuam na mesma escola e criaram com seus alunos a história "Nhonhoco". A professora 1 possui uma turma de alunos de $1^{\underline{a}}$ série do Ensino Fundamental, sendo que a participação na criação desta história contou com a colaboração de 3 meninos. A professora 2 atua no Laboratório de Informática e auxiliou nesta criação, inclusive fazendo o papel de narradora. Em um primeiro momento, na sala de aula, a professora 1 propôs aos seus alunos a criação de uma história com recursos de áudio e perguntou à turma com qual história iriam trabalhar. Um dos alunos, de 7 anos, lembrou de uma história que seu pai sempre contava, mas ele não lembrava todo o enredo. A professora fez o seguinte registro:

A história de Nhonhoco, segundo $F$ que é meu aluno de 7 aninhos, foi contada por seu pai. Mas só o que ele sabia dessa historinha era que existia na floresta uma minhoquinha que adorava passear durante o dia. Com isso fui perguntando aos outros alunos que nome dar a minhoquinha, e como nesse dia só havia homens na sala, houve alguns(sic) sugestões do tipo: 
Mimi, Minhocão, Nhonhoquinha até que resolvemos por Nhonhoco. Para ilustrar mais e ficar mais divertida fui perguntando quem queria fazer o papel de outros animaizinhos, e logo foram dizendo: Tia eu quero ser um pássaro, e outro disse: eu quero ser um gafanhoto. A aula foi animadíssima, e todos gostaram. (Professora 1).

Foi combinado com os alunos a re-elaboração da história através de um áudio. A história inicia com a narração da professora 2 sobre a floresta e os animaizinhos que ali residem e no seu transcurso participam os alunos com limitação visual, dialogando nas vozes dos personagens da história. Os recursos sonoros dos animais foram pesquisados no ambiente virtual e possibilitam aos ouvintes identificá-los com muita facilidade. Os sons imitam o gato, o cachorro, o lobo, a vaca, o sapo, entre outros bichos. A narrativa inicia descrevendo o inverno, com sons de chuva, ventos, relâmpagos e trovões. Surge a personagem principal, a minhoquinha Nhonhoco, que elogia a chuva, dizendo: Que beleza de dia! Um passarinho pergunta se ela enxerga bem. $O$ gafanhoto dá a sua opinião dizendo que ela deve gostar de tomar banho. Ao parar a chuva, Nhonhoco fica muito feliz e convida os seus amigos para um passeio. Ao som de passarinhos, de passos e da natureza, os animaizinhos passeiam pela floresta observando as cores das flores, o desenho das folhas, entre outros. Um passarinho pergunta se ele gosta do dia. Nhonhoco diz que gosta do dia, do sol, da lua, da chuva... tudo apareceu em um tempo certo e de um jeito diferente. Todos adoraram o passeio e a partir deste dia passaram a ver a natureza de uma forma diferente. No final, todos concluem: O dia é mesmo uma beleza!!!

A história tem a participação dos alunos desde o início até o final, representando os personagens principais. Mesmo possuindo limitação visual, os alunos utilizam os termos "enxergar", "ver". Sua relação com o mundo, com as histórias possibilita que se sintam incluídos em uma sociedade que essencialmente é visual. Seus modos de ver o mundo, através do tato, da audição, permitem que criem histórias, utilizem a imaginação.

Percebe-se que, apesar das dificuldades e barreiras na realização da atividade proposta, ao invés de justificar o "não fazer", os professores e alunos lançaram-se ao desafio e saíram vencedores. Vygotsky afirmava, "que perspectivas se abrem ante um pedagogo quando sabe que o defeito não é só uma carência, uma deficiência, uma debilidade, senão também uma vantagem, um manancial de força que existe, em certo sentido, positivo! " $E$ continuava: "nesta oposição entre a deficiência organicamente dada e os desejos, fantasias, sonhos, é dizer, as tendências psíquicas à compensação, estão implícitas no ponto de partida e nas forças motrizes de toda educação." (VYGOTSKY, 1997, p.46).

Percebe-se, nas duas situações, na seleção das histórias, nas falas e na participação das professoras e dos alunos com limitação visual, que Vygotsky tinha razão quando afirmava que "a palavra vence a cegueira".(VYGOTSKY, 1997, p.108).

Por outro lado, em nenhum momento as professores e os alunos sentiram-se incompetentes ou "deficientes" para realizar a atividade, diante das tecnologias eletrônicas.

\section{CONSIDERAÇÕES FINAIS}


Pode-se constatar que ambas as histórias narradas pelos alunos são 0 resultado de uma atividade proposta, inicialmente, para os seus professores e que chegaram até eles fruto de um desafio e da crença de que seria possível realizá-la ou pelo menos valia a tentativa desta construção. $O$ software trabalhado na atividade proposta possuía recursos visuais e sonoros. No primeiro momento, quando foram desafiados a realizar a atividade das narrativas com histórias em quadrinhos, surgiu a primeira dificuldade para as PNEEs com limitação visual, em função do uso de imagens, fato este que seria o empecilho e o pretexto para não realizarem a atividade. No entanto, diante da dificuldade da execução da tarefa, os professores/alunos com limitação visual não esmoreceram e sentiram-se motivados a assumir o compromisso, não apenas com o seu aprendizado, mas com o grupo do qual faziam parte e com seus alunos, que também participavam dessa construção e não poderiam ser excluídos da atividade proposta, pela dificuldade presente.

E qual seria o caminho para solucionar este problema? A busca de outros softwares, o compartilhar com os colegas/formadores/monitores, a coragem de enfrentar os desafios, a superação das limitações impostas pela tecnologia e pela falta de visão, a motivação de professores que tem um compromisso com os seus alunos de serem mediadores no seu processo de construção do conhecimento. E diante de tantas alternativas, os professores ousaram, acreditaram nas suas potencialidades e levaram os seus alunos a caminhos nunca percorridos. Os professores encantaram e foram encantados pelos seus alunos. Surpreenderam quando dividiram as suas angústias, as dificuldades e que estas, com a ajuda de cada um, foram superadas pelo grupo e, quando descobriram, que eram capazes, inventaram, reinventaram, indo muito além da proposta inicial.

São narrativas que trazem a sua marca, a sua criação. Se na história tradicional eram três porquinhos, hoje são dois porquinhos e uma porquinha. E mesmo sem enxergarem com os olhos, estas crianças puderam ver através do Nhonhoco, que tem este nome porque eles criaram. Nas histórias ficou gravada a sua representação, não são a simples reprodução de uma história pronta, pois trazem consigo muito de $\mathrm{si}$, muito dos outros. $\mathrm{E}$ hoje, como os personagens da história que podem achar o dia de chuva bonito, os professores e alunos acreditam que podem fazer diferente, pois todos somos diferentes, mas os objetivos foram atingidos da mesma maneira.

Este é o papel do professor, aquele que provoca, instiga, que possibilita ao aluno ser agente do seu processo de aprendizagem; que permite que o aluno seja capaz e que se sente capaz de enfrentar os desafios, de romper as barreiras, de construir, de reconstruir, de criar, de recriar; um professor que sabe o que quer e que é encantado pelo seu fazer, que faz uso das tecnologias como um meio e não como um fim; que busca resignificar o processo de ensino e de aprendizagem através da colaboração, do compartilhamento e da cooperação entre os pares; que propicia a co-construção do conhecimento; que faz da vida um eterno aprendizado e que busca, no encantamento, a chave para a superação das dificuldades e a porta da entrada para a inclusão social e digital.

REFERÊNCIAS: 
ESTABEL, Lizandra B. ; MORO, Eliane. A Leitura e seus Mediadores como Inclusão Social de PNEEs com Limitação Visual. IN: Congresso Internacional de Educação, 4, 2005, São Leopoldo, UNISINOS, 2005. [CD-ROM]

O Acesso às Tecnologias de Informação e de Comunicação

e a Superação das Limitações dos Pnees com Limitação Visual Incluindoos em um Ambiente de Aprendizagem Mediado por Computador. Disponível em:

http://www.cinted.ufrgs.br/renote/maio2005/artigos/a16_ticscegos.pdf. Acesso em: 15 ago.2005.

LOPES, Rosana Pereira. Um Novo Professor: novas funções e novas metáforas. In: Redes Digitais e Metamorfose do Aprender. Petrópolis-RJ : Vozes, 2005. P.33-55.

MOLINA, Olga. Leitura: será possível uma definição? In: Leitura: teoria \& prática. Porto Alegre: Mercado Aberto/ ALB, 1982.

NUÑEZ, Gabriel et alii. Tendências na Comunicação. Porto Alegre: L\&PM, 2000.

PASSERINO, Liliane M. ; SANTAROSA, Lucila M. Costi. Análise da Interação Social Através de Chat com Sujeitos com Autismo. Disponível em:

$<$ http://www.niee.ufrgs.br/ribie2004/Trabalhos/Comunicacoes/com95-105.pdf $>$.

Acesso em: 15 ago. 2005.

. Vygotsky e os Ambientes Telemáticos. Disponível em: http://libra.niee.ufrgs.br/ proinesp/amb_dig/index.html. Acesso em: 2 abr. de 2003.

PASSERINO, L. M.; SANTAROSA, L. M. C. REGO, T. C. Vygotsky: uma perspectiva histórico cultural na educação. Petrópolis: Vozes, 1995.

SILVA, Ezequiel Theodoro da . O Ato de Ler. São Paulo: Cortez, 1981.

VYGOSTKY, L. S. A Formação Social da Mente. São Paulo: Martins Fontes, 1984.

Obras Escogidas V: fundamentos de defectologia. Trad.

Castellana de Julio G. Blank. Madrid : Visor, 1997.

VIGOTSKII, L. S.; LURIA, A. R.; LEONTIEV, A. N. Linguagem, Desenvolvimento e Aprendizagem. $2^{2}$ ed. São Paulo: Ícone, 1988. 